\title{
A EDUCAÇÃO AMBIENTAL COMO PRÁTICA PROMOTORA DE INTERAÇÃO NO CONTEXTO ESCOLAR
}

\author{
Priscila Wally Virissimo Chagas ${ }^{1}$; Janaína Amorim Noguez²; Narjara Mendes Garcia ${ }^{3}$
}

\section{RESUMO}

O texto em questão apresenta a análise de um projeto de Educação Ambiental desenvolvido tendo como contexto uma escola da rede municipal de Rio Grande/RS. Através da metodologia Inserção Ecológica e dos estudos teóricos da Bioecologia do Desenvolvimento Humano de Urie Bronfenbrenner (19172005), buscamos responder ao seguinte problema de pesquisa: Ao estabelecer os conceitos proximais de Reciprocidade e Afetividade nas práticas de Educação Ambiental na escola, educadores e educandos estabelecem Díades promotoras de desenvolvimento humano? Desta forma, emerge ainda, a discussão conceitual sobre o princípio de Pertencimento como fundamental na constituição de projetos de Educação Ambiental no ambiente escolar, tendo como conclusão que tais ações fazem emergir a reciprocidade e a afetividade na relação professor-aluno.

Palavras-chave: Educação Ambiental; Pertencimento; Bioecologia do Desenvolvimento Humano.

\section{ENVIRONMENTAL EDUCATION AS A PRACTICE THAT PROMOTES INTERACTION IN THE SCHOOL CONTEXT}

\section{ABSTRACT}

This text presents the analysis regarding an Environmental Education project developed in a school of the municipal network of Rio Grande/RS. Through the Ecological Insertion methodology and Urie Bronfenbrenner's theoretical studies on the Bioecology of Human Development (1917-2005), we sought to answer the following research problem: In establishing the proximal concepts of Reciprocity and Affectivity in the practices of Environmental Education in school, do educators and students create dyads of human development promotion? This way, the conceptual discussion about the principle of Belonging as fundamental in the constitution of Environmental Education

1 Mestre em Educação - PPGEDU/FURG. Doutoranda do Programa de Pós-Graduação em Educação Ambiental - PPGEA/FURG e E.M.E.F. Frederico Ernesto Buchholz. priwallyfurg@gmail.com.

2 Mestre em Educação Ambiental pelo Programa de Pós-Graduação em Educação Ambiental PPGEA/FURG. Doutoranda PPGEA/FURG. Pedagoga - coordenadora pedagógica do Centro de Atenção Integral à Criança e ao Adolescente - CAIC/FURG. E-mail: janainanoguez@furg.br. 3 Doutora em Educação Ambiental - Programa de Pós-Graduação em Educação Ambiental PPGEA/FURG. Professora Adjunta do Instituto de Educação da Universidade Federal do Rio Grande - FURG. E-mail: narjaramg@gmail.com. 
projects in the school environment also arises, having as conclusion that such actions promote the occurrence of reciprocity and affectivity in the teacherstudent relationship.

Keywords: Environmental Education; Belonging; Bioecology of Human Development.

\title{
Introdução
}

Dentre as discussões e vertentes que permeiam a Educação Ambiental - EA está à consolidação da mesma nos espaços de educação formal, mais precisamente, apontamos o contexto ecológico escolar. Embora haja a ampliação da compreensão de que a EA entende o sujeito e o meio de forma unificada, nas instituições de Educação Básica os projetos ambientais ainda são fortemente ligados ao princípio da sustentabilidade e ações preservação dos os recursos naturais para que as gerações futuras possam aprender comportamentos mais sustentáveis. Existe um foco muito grande nas datas comemorativas e ações pontuais sobre o cuidado com o meio ambiente, distanciando-se da necessidade de ações em Educação Ambiental com ênfase nos princípios do pertencimento e interação ambiental, fundamentais para que se construa uma consciência ecológica.

Pensando a Educação Ambiental no Contexto das escolas, Meirelles e Santos (2005) dizem:

\begin{abstract}
A educação ambiental, e uma atividade que não pode ser percebida como mero desenvolvimento de "brincadeiras" com crianças e promoção de eventos em datas comemorativas ao meio ambiente. $\mathrm{Na}$ verdade, as chamadas brincadeiras e os eventos são parte de um processo de construção de conhecimento que tem o objetivo de levar a uma mudança de atitude. $O$ trabalho lúdico e reflexivo e dinâmico e respeita o saber anterior das pessoas envolvidas (MEIRELLES E SANTOS, 2005, p. 34).
\end{abstract}

Salientamos que não há a intencionalidade da crítica de tais ações, mas sim, de percebemos que emerge a indigência de que o entendimento da dimensão sistêmica da EA necessita, mais propriamente, da conscientização de que ser humano e meio ambiente ecológico estão em constante ligação, isto é, há desenvolvimento humano e uma forte interação quando os mesmos se modificam um para adaptar-se ao outro (BRONFENBRENNER, 1996).

Sobre pertencimento entendemos como um princípio repleto de 
sentidos para aqueles que acreditam que as relações no mundo não estão dadas, pois são processos e como tal estão situados em uma temporalidade espacial possuidora de significados socioculturais construídos em diferentes contextos. Estes contextos (ou lugares) se apresentam, metaforicamente falando, como palco das relações humanas que se utilizam dos signos e símbolos para estabelecer interação, produzindo comunicação - relação contradição e mudança.

Partindo de tal compreensão, objetivamos apresentar a escola como um ambiente ecológico promotor de desenvolvimento humano e interação entre professor-alunos-ambiente, sendo, a relação educador e educando o fio condutor central mediados pelo ambiente. A Bioecologia do Desenvolvimento Humano de Urie Bronfenbrenner (1917-2005) contribui para a construção do olhar ecológico sobre as relações ambientais no contexto escolar, pois dimensiona quatro categorias de análise na compreensão desse fenômeno, sendo: Pessoas; Contextos; Tempo; Processo. Trata-se de uma abordagem teórico-metodológica que aponta as quatro categorias citadas como interligadas, ou seja, uma ação influencia a outra nos acontecimentos que a permeiam.

Como problemática de pesquisa, buscamos responder ao seguinte questionamento: Ao estabelecer os conceitos proximais de Reciprocidade e Afetividade nas práticas de Educação Ambiental na escola, educadores e educandos estabelecem Díades promotoras de desenvolvimento humano?

Este texto terá como Contexto a análise de uma escola pública na cidade do Rio Grande/RS, a qual chamaremos de F, e apresenta como metodologia a Inserção Ecológica, na qual Cecconello e Koller (2004) procederam a sistematização deste método de pesquisa, deixando claro que o estabelecimento de vínculos entre pesquisador e pesquisado pode levar a dados mais fiéis, já mostrando que ao criar esta vinculação, geramos o equilíbrio de poder, no qual passa a existir reciprocidade entre ambos (Bronfenbrenner, 1996). Ao utilizar-se da Inserção Ecológica, o pesquisador tem a ciência de que não se procede a pesquisa em um único momento de encontro, mas sim, na imersão e vinculação criada, uma vez que as autoras recomendam o uso de meios menos formais do que os procedimentos metodológicos padrões. 
O que instigou analisar a prática de Educação Ambiental na instituição referida se deve ao fato de tratar-se de um projeto pensado e construído a partir de um olhar sistêmico dos contextos que permeiam os estudantes e educadores. A Inserção Ecológica no ambiente natural da pesquisa, a escola $F$, permite que, enquanto pesquisadoras, tenhamos contato direto com as quatro categorias propostas por Bronfenbrenner (1917-2005), Pessoas estudantes e educadores; Contexto - escola F; Tempo - deslocamento histórico-evolutivo que motiva a prática da instituição; Processo - Projeto de Educação Ambiental como grande "guarda-chuva" potencializador do pertencimento.

Compreendemos ainda que seja fundamental delimitar nosso lugar de fala como pertencentes e pesquisadoras do Programa de Pós-Graduação em Educação Ambiental - PPGEA/FURG, na linha de pesquisa Educação Ambiental: Ensino e Formação de Educadores (as). Dentro de nossas pesquisas, bem como, no presente texto, temos como principal referencial teórico os estudos de Urie Bronfenbrenner a respeito da Bioecologia do Desenvolvimento Humano, buscando demonstrar a importância desta para o campo da Educação Ambiental.

Como forma de organização, estabelecemos os seguintes eixos de análise teóricos que serão trabalhados ao longo do texto: a) O Contexto da Prática de Educação Ambiental no Ensino Formal; b) A Díade Professor-Aluno na Bioecologia do Desenvolvimento Humano.

\section{O pertencimento no contexto escolar como ecologia das ações de educação ambiental}

Antes de abordar o contexto como uma categoria de análise dentro da teoria Bioecológica defendida por Bronfenbrenner (1996) acreditamos que se faça necessário dialogar e provocar a pensar sobre 0 sentido de pertencimento. A que significados o pertencimento está ligado? O que significa, afinal, pertencer? Sentir-se pertencente a uma situação, a um grupo, a um espaço, enfim, tantas são as reflexões possíveis ligadas a essa categoria estritamente subjetiva e demasiadamente humana. Tentaremos provocar a reflexão...

Vale destacar que essa categoria não aparece nos estudos científicos 
mais tradicionais. Essa discussão está fora das reflexões e construções teóricas da ciência tradicional que precisa ser validada com auxílio de instrumentos precisos e que em sua metodologia seja capaz de mensurar, comparar e cria novas deduções. Para esse tipo de produção científica o pertencimento aparece como algo menor, não se discute, é indiferente, não auxilia a categorização objetiva de um conjunto de análise.

Para Oliveira (2014) pertencimento é uma categoria construída a partir do conceito de lugar, a saber: "o sentido de lugar implica o sentido da vida e, por sua vez, o sentido do tempo" (2014, p.3). A autora ainda acrescenta que:

\begin{abstract}
A definição de lugar se mescla, se confunde com espaço ocupado (...) Lugar e tempo se apresentam, frequentemente, intimamente ligados. Percebemos e sentimos a realidade temporal acoplada ao lugar, ao espacial (...) A concepção atual de lugar é de tempo em espaço: ou seja, lugar é tempo lugarizado, pois entre espaço e tempo se dá o lugar, o movimento, a matéria. (OLIVEIRA, 2014, p. 4/5).
\end{abstract}

Nota-se que a autora provoca a pensar os lugares como espaços de pertencimento. Há aí, o estabelecimento de uma relação entre esses dois conceitos para sustentar um significado mais amplo. Neste mesmo sentido, ainda temos Relph (2014) nos apresentando o conceito de identidade e Mello (2014) discutindo a experiência humana. Pertencimento como o resultado de uma equação que adiciona lugar, identidade e experiência humana.

Num primeiro momento, estes conceitos podem parecer estar ligados às ciências do Comportamento (com a Psicologia, por exemplo). Porém se percebermos o avanço da Ciência coadunado com a potência de novas relações homem-natureza perceberemos a construção do conhecimento a serviço da capacidade humana de melhor desenvolver conhecimento e tecnologia de forma sustentável.

Berdoulay e Entrikin (2014) afirmam que “(...) O desejo de pertencimento do indivíduo ao grupo e do grupo ao meio pode ser compreendido como um processo essencialmente subjetivo" (2014, p.107). Esse excerto nos auxilia a pensar na necessidade humana de sentir-se situado, acolhido, pertencente. $E$ que todas essas questões acontecem em um corpo.

Chaveiro (2014) afirma que é na corporeidade que acontecem as experiências sensoriais com os significados e as mediações. O corpo, para esse autor, é um guardador de lugares, uma espécie de mediação entre a 
genética e a cultura; experimentam-se os lugares com o corpo, “(...) mediante as ações sociais do trabalho, afetivas, sensoriais e no logro dos conflitos do mundo" (2014, p.277).

Sendo assim, é no corpo que se darão as experiências humanas, 0 processo de construção de identidade (que vai até a morte do sujeito), o significado dos lugares e tudo isso constituirá o que estamos chamando de sentimento de pertencimento. Sentir-se pertencente aos lugares em que estabelecemos nossas relações interpessoais. Tais relações, dentro da Bioecologia do Desenvolvimento Humano, são percebidas através das interações promovidas pelas Díades apontadas por Bronfenbrenner (1996) nas quais há a relação de reciprocidade e o desenvolvimento que ocorre entre pares. As díades foram sistematizadas em três: De Ação Conjunta, Primária e Observacional. A de Ação Conjunta ocorre quando os sujeitos realizam as ações de maneira coletiva, um agindo sobre o comportamento do outro e estabelecendo assim mudanças nos padrões de comportamento. Na Díade Observacional, o sujeito pode não estar agindo diretamente, mas está em desenvolvimento ao observar a ação dos demais indivíduos, enquanto que na Primária, há a lembrança do que foi feito e desenvolvido, bem como, a aplicação em outros microssistemas.

Considerando o ser humano na sua experiência integral, é ontológico pensar em pertencimento. Este significado está arraigado ao sentido da vida, a sobrevivência, pois os humanos são seres de interação ambiental e não apenas corpos programados para executar ações e estabelecer determinados comportamentos. Pertencimento, lugar, experiência e identidade, por exemplo, aparecem no tempo e no espaço a partir do entendimento de tempo e espaço mediados, tempo e espaço lugarizados.

Pertencimento também pode estar associado à pesquisa nas Ciências Humanas por conta da necessidade da relação de identidade entre 0 pesquisador e o "objeto". Isto significa dizer que o pesquisador, possivelmente, estabelece uma relação entre ciência e empiria por um determinado motivo, por uma determinada justificativa, um por quê. Arriscamos aqui a afirmar que certamente essa força motriz, essa mola propulsora que conduz 0 ato cognoscente realizado pelo sujeito da investigação é tangenciada pelo sentido de pertencimento, uma potência geradora de curiosidade epistemológica e 
excitação pelo processo a ser conhecido. Capra (1982) já apontava que a rigidez de estruturas comportamentais e padronizações sociais fazem com que a sociedade não tenha sua capacidade de levar adiante a evolução dos processos que a sustentam, sendo assim, urgente a necessidade da Educação Ambiental na educação formal mediada pelo pertencimento ao lugar e a promoção de cuidado e afetividade nas interações ambientais.

A Teoria Bioecológica do Desenvolvimento Humano dialoga sobre a importância dos processos proximais, das relações interpessoais (díades). Destaca que essas díades possuem subcategorias, a saber: afetividade, equilíbrio de poder e reciprocidade. Nesta abordagem a funcionalidade do conhecimento no contexto escolar necessita percorrer os caminhos da promoção humanização, a partir do equilíbrio das relações entre professoralunos-ambiente, tendo como base princípios como pertencimento e construindo o saber a partir daquilo que nos move, nos potencializa enquanto seres humanos.

Bronfenbrenner (2011) revê a sua própria teoria (Teoria Ecológica do Desenvolvimento Humano) propondo a Teoria Bioecológica do Desenvolvimento Humano. Nesta última, o autor sugere a análise do desenvolvimento vital a partir de um esquema chamado PPCT, ou seja, a análise dos fenômenos e o estabelecimento das relações entre eles ocorrerá a partir desta proposição. Com o objetivo de estabelecer um diálogo com essa abordagem, colocaremos em relação a categoria contexto e pertencimento, que intuitivamente nos parece completamente possível por estabelecerem entre si elementos em comum, como o sentimento de presença, identidade e lugaridade a partir da Inserção Ecológica na escola F.

Através da Inserção Ecológica, que possibilita às pesquisadoras um acompanhamento sistemático e que não se resume em apenas um único encontro formal, observamos o contexto da escola $F$ durante um semestre, tendo acesso ao texto base do projeto pautado na Educação Ambiental e assim procedendo a análise documental do mesmo, bem como, através de conversas informais e observações do cotidiano, tivemos acesso então às práticas ali desenvolvidas.

Dentro da Bioecologia do Desenvolvimento Humano, o Contexto no qual a pesquisa se desenvolve tem fundamental importância na compreensão 
do que se objetiva, visto que, este ambiente ecológico aponta ao pesquisador tanto as relações interpessoais que se apresentam, bem como, o desenvolvimento sistêmico constante entre as Pessoas e o meio, é nele que se dão os processos proximais, bem como, abarca, diversos microssistemas que influenciam na vida cotidiana dos sujeitos. Tudge (2008) considera que o Contexto pode apresentar características que exercem influência diretamente nas relações estabelecidas e, com isso, promove desenvolvimento.

O Contexto em questão, a escola F, localizada em um bairro de periferia da cidade de Rio Grande/RS, há atualmente 725 estudantes divididos desde a Educação Infantil até os Anos Finais do Ensino Fundamental e, segundo justificativa do projeto, bem como, presente na fala da equipe gestora, duas dificuldades foram percebidas ao longo dos anos e culminaram na necessidade da elaboração do mesmo, sendo estas: a) a urgência de trabalhar com questões de afetividade entre os pares; b) a necessidade da presença da Educação Ambiental naquele lugar não mais como projetos isolados e direcionados apenas às datas comemorativas, mas sim, como protagonista das ações desenvolvidas naquela escola.

A concepção de Educação Ambiental exposta no projeto em questão dialoga com a Política Nacional para a Educação Ambiental - Lei №. 9795 de 27 de abril de 1999 quando em seu Art. 1ํ diz que:

\footnotetext{
Entendem-se por educação ambiental os processos por meio dos quais o indivíduo e a coletividade constroem valores sociais, conhecimentos, habilidades, atitudes e competências voltadas para a conservação do meio ambiente, bem de uso comum do povo, essencial à sadia qualidade de vida e sua sustentabilidade. (BRASIL, 1999, p.1).
}

Baseadas na concepção de Educação Ambiental exposta e percebida no Contexto, bem como, nos argumentos que motivaram a construção do mesmo, compreendemos que foi percebida a necessidade de trazer a Educação Ambiental como forma de, coletivamente, construir uma comunidade escolar pautada nos princípios da EA, de modo a que os educandos passassem a ser capazes de usufruir do ambiente baseados no pertencimento ao ambiente escolar.

O projeto denominado $F$ : nosso ambiente de pertencimento, já em sua justificativa expressa a importância de fazer com que os estudantes se 
compreendessem como parte daquele ambiente ecológico para que assim, criassem uma relação de pertencimento com o lugar e, a partir disso, novas regras de convívio sustentável fossem sendo estabelecidas. Em nossas Inserções, ficou explicito que o objetivo principal estava centrado nos Processos Proximais, ou seja, os estudantes estavam de fato inseridos nas atividades de maneira regular, efetiva e reciproca (NARVAZ E KOLLER, 2004). Para tanto, todos os estudantes e professores, desde a Educação Infantil aos Anos Finais, foram motivados a participar de uma maneira permanente, sendo que cada modalidade de ensino e área do conhecimento tinha a autonomia de desenvolver atividades ligadas ao projeto inicial.

Fazendo um necessário recorte na explicação das ações ambientais desenvolvidas na escola $F$ e visando atender ao problema de pesquisa exposto, utilizaremos como referência as atividades da disciplina de Relações Humanas, ministrada pela professora $L$, com a qual realizamos a maioria das Inserções. $L$ desenvolve suas aulas com todas as turmas dos Anos Finais (do $6^{\circ}$ ao 9a ano) o que possibilita a ela ter um mapa ecológico das situações que se apresentavam de maneira mais intensa. Segundo ela, ao longo dos anos, foi percebendo que faziam (enquanto escola) práticas de Educação Ambiental isoladas, isto é, cada educador, dentro de sua sala de aula, trabalhava com questões pertinentes à temática, mas que não ultrapassavam a barreira daquele lugar. Havia sim, pertinência e conscientização, mas a mesma entende que trazer a EA para o contexto escolar visa que aquilo que for trabalhado gere, de alguma forma, um resultado para a sociedade, ou seja, para além da criança ou do adolescente conscientizar-se da separação do lixo, mas sim, reverter aquilo em prática social, ou seja, é a subjetivação de valores éticos e à prática cotidiana. Ainda segundo o entendimento da educadora, não se deve abandonar as tradicionais práticas de EA desenvolvidas nas escolas, mas sim, fazer com que estas sejam utilizadas na prática social.

A educadora percebeu ainda que tem ficado evidente que muitos educandos usam o patrimônio escolar sem consciência de que ali se trata de algo que não pertence somente a eles, mas sim, a todas as gerações vindouras. Assim, definiu que para ampliar a prática da Educação Ambiental, teria que partir conscientizando aqueles sujeitos do que era o seu ambiente, trazendo assim, pertencimento. Para além disso, dinamizar que a coletividade 
precisava andar de mãos dadas com as ações que fossem ser criadas e com isso, possivelmente fosse capaz de melhorar as relações entre os pares, situações de bullying, exclusão, depressão adolescentes, são entendidas por ela como problemáticas ambientais, pois "Quando sequer cuidados do nosso Eu, não temos a dimensão dos problemas ambientais". (Professora L.)

O pensamento da professora L dialoga com Janke e Tozoni-Reis (2008):

[...] o papel da educação ambiental é ajudar a revelar, a si e ao outro, a responsabilidade histórica dos sujeitos para a realização de uma sociedade mais justa e igualitária, sua tarefa é proporcionar condições para que possam interpretar o ambiente em que vivem. Esta interpretação requer muito mais do que conhecimentos sobre condições ambientais favoráveis: tem dimensão subjetiva, no sentido do reconhecimento das necessidades individuais e coletivas, participação e comprometimento com a luta social e emancipatória por um ambiente saudável, que significa melhoria na qualidade de vida (JANKE E TOZONI-REIS, 2008, p. 149).

Buscando então a citada melhoria na qualidade de vida naquele Contexto, cada turma ficou responsável por duas tarefas primordiais, sendo: 1). Desenvolver uma ação coletiva de Educação Ambiental que tivesse como pauta principal a afetividade e 2). Desenvolver uma prática de Educação Ambiental que demonstrasse Pertencimento com a escola. Afinando o recorte, destacamos as ações realizadas por uma turma de $8^{\circ}$ ano que, num primeiro momento solicitou uma palestra com a Psicopedagoga da instituição na qual ela pudesse abordar o sentido de coletividade com os pares, para que assim, pudessem estabelecer díades que fossem promotoras do desenvolvimento da afetividade, não somente entre os estudantes, mas, também na relação com os educadores. Yunes e Juliano (2010) apontam que as relações diádicas são promotoras de sentimentos recíprocos entre os envolvidos, gerando relações afetivas positivas por um longo curso da vida se forem estimuladas. A partir da palestra, diversas dinâmicas foram desenvolvidas, tais como: troca de bilhetes anônimos com frases de estímulo, bilhetes com missões foram entregues aos professores nas quais deveriam fazer coisas simples como ser gentil com um desconhecido, pedir desculpas para alguém por algum motivo, ainda foram trabalhadas com músicas com temáticas sugeridas pelos estudantes entre outras situações. 
Capra (1996) aponta que em qualquer sistema vivo há interação e, se assim há, beiramos uma mudança de paradigma que aproxima nossa sociedade de um olhar voltado para o todo, não mais de partes dissociadas e neste diálogo com o citado autor, percebemos a compreensão que se objetivou gerar no Contexto da escola $F$. A reciprocidade está presente na interação dos sujeitos com o contexto, gera desenvolvimento e crescimento nas situações que envolvem a si e ao outro, consequentemente, o ambiente ecológico escola, passou a ser visto como lugar de pertencimento e notáveis modificações na forma de ser e estar no mundo escolar foram percebidas, levando ao segundo objetivo da educadora de desenvolver prática de Educação Ambiental que demonstrasse o pertencimento. O que saltou aos nossos olhos foi a campanha de cuidado com as salas de aula, limpeza e manutenção de lugares da escola, bem como, elaboração de cartazes distribuídos por todo aquele ambiente ecológico com frases sobre a importância da valorização da vida, sempre pautadas que cuidar-se enquanto sujeito dotado de subjetivações, gerava um bem coletivo.

Compreendemos assim que para despertar nos estudantes 0 pertencimento à Escola como um ambiente ecológico e que isso, posteriormente, se transformasse em cuidado com o ambiente como um todo, necessitaríamos do aporte da Educação Ambiental oferta, dialogando com Grun (1996, p. 60) quando diz que: “(...) o ambientalismo parece surgir como um grande guarda-chuva sob o qual todas as 'outras crises' podem encontrar guarita". Ou seja, partir de algo muito próximo à realidade daqueles sujeitos.

\section{A díade professor-aluno na Bioecologia do Desenvolvimento Humano}

Como já foi abordado, a Teoria Bioecológica do Desenvolvimento Humano defende o padrão PPCT. Analisa o desenvolvimento humano a partir desta categoria que, de forma sistêmica, percebe as relações no mundo. A tentativa que se pretende nesta seção é a de dialogar com o conceito de contexto, especialmente o contexto escolar, como lugar, um espaço-tempo lugarizado onde se estabelecem vínculos, estes, centrados nas díades, especialmente entre professores e alunos com base na afetividade.

Poletto e Kolller (2008) apontam que na Teoria Ecológica do Desenvolvimento Humano, Bronfenbrenner analisa o contexto a partir de 
alguns níveis ambientais, “(...) O primeiro componente do modelo bioecológico, o contexto (...) e é analisado por meio da interação de quatro níveis ambientais, denominados: microssistema, mesossistema, exossistema e macrossistema." (2008, p.2). Todos estes exercem influência direta e indiretamente nos padrões de comportamento dos indivíduos. Os microssistemas são todos os contextos nos quais cada um está inserido (escola, família, grupos sociais), enquanto que no mesossistema estabelecem-se relações entre outros microssistemas, ou seja, com as demais vivências dos que convive (colegas, professores). Nos exossistemas estão os centros de poder, como a secretaria de educação, por exemplo, que exerce influência direta nas atuações da escola. Em nível macrossistêmico estão as deliberações que são pensadas para os estudantes e grupo de educadores, mas que estes não exercem interação direta, tais como as legislações vigentes.

A afirmação acima diz da revisão de literatura feita pelo próprio autor em sua obra. Num primeiro momento Urie Bronfenbrenner disserta sobre alguns níveis ambientais em que acontecem as relações, de um nível mais imediato até um grau mais distanciado do sujeito (o macrossistema), porém tão importante e influente quanto.

É a partir das interações tecidas no contexto escolar que debruçamos nossas análises, por em relação os referenciais que nos embasam para dialogar com esses autores, dissertar sobre tais questões e retomar a sistematização objetivando uma questão, algo que possa nos auxiliar enquanto pesquisadores a repensar, avaliar, refletir sobre nossas práticas.

Falar sobre contexto escolar nos remete, quase que imediatamente, a pensar os processos de aprendizagem. As relações neste contexto possuem como força motriz a aprendizagem do conhecimento sistematicamente considerado como válido ao longo da história da humanidade. Alguns poderão afirmar que na escola outros saberes também são produzidos. Certamente sim, existe um currículo que não se mensura, não se prescreve antecipadamente, se esvai pelas mãos das políticas públicas educacionais ou pelos sujeitos protagonistas do processo. Porém, aqui falaremos sobre aquilo que está posto como conhecimento válido a ser dialogado no ambiente escolar, aquilo que é dever da instituição escolar (baseado naquilo que Cortella (2018) afirma ser o papel da escola): ensinar. 
Resgatando a problemática inicial de que "Ao estabelecer os conceitos proximais de Reciprocidade e Afetividade nas práticas de Educação Ambiental na escola, educadores e educandos estabelecem Díades promotoras de desenvolvimento humano". No Contexto da escola F podemos perceber em nossas Inserções Ecológicas, bem como ao ter relatos dos envolvidos no projeto, que o desenvolvimento dos pares se deu ao longo do processo de construção das atividades que permearam o projeto, isto é, de forma contínua como produtoras de mudanças estruturais e significativas dentro de um espaço-tempo. Há, além da interação entre os pares, estabelecimento de afetividade e consequente alteração dos indivíduos com o meio que os cerca, dando significado ao objetivo da Educação Ambiental como processo crítico e emancipatório. Ao se estabelecer uma relação direta e continua com 0 ambiente em que estão envolvidos, temos o que chamamos na Bioecologia do Desenvolvimento Humano de processos proximais.

Bronfenbrenner (1996) dimensiona que as atividades estabelecidas em conjunto, agem sobre o desenvolvimento dos sujeitos e criam, com isso, padrões de atividade que podem se constituir em mudanças significativas em suas características. Na inserção no contexto da escola $\mathrm{F}$, tanto estudantes da turma em questão, bem como, demais professores e gestão, em conversas informais, deixaram evidente que muitas relações afetivas se modificaram a partir das atividades realizadas. Ainda, que, passam a perceber que a escola se constitui em um ambiente ecológico para todos e assim, criando um padrão de pertencimento. Bronfenbrenner (1996) aponta que:

\begin{abstract}
A forma, o vigor, o conteúdo e a direção dos processos proximais que levam a cabo o desenvolvimento, variam sistematicamente como uma função conjunta das características da pessoa que se desenvolve; do ambiente - tanto imediato quanto mais distante - no qual os processos ocorrem; da natureza dos aspectos do desenvolvimento estudados e das continuidades e mudanças sociais que acontecem ao longo do tempo no curso de vida e no período histórico durante o qual a pessoa viveu (BRONFENBRENNER, 1996, p. 204).
\end{abstract}

Entre os principais papéis da Educação Ambiental está o fato de ser promotora da capacidade de fazer com que os sujeitos repensem o seu papel social, modifiquem suas formas de ser e estar no mundo e, sobretudo, suas ações sobre o ambiente vivido. Promover ações ambientais como as que aqui foram explicitadas, trouxe àquele contexto uma importante ferramenta de 
valorização da vida em sociedade e da conservação do meio para as gerações que virão. Neste sentido, fortemente foi percebida a questão da reciprocidade na forma de ação dos sujeitos envolvidos nas ações uns com os outros, relações de cuidado consigo, com o outro e com o meio, como propulsoras do desenvolvimento.

A partir da reciprocidade gerada nas ações diádicas, podemos perceber que mesmo quando um sujeito não está em ação direta na díade, seu desenvolvimento ocorre a partir do desenvolvimento do outro, seja por observação ou interação direta, o que promove o que a Bioecologia denomina como equilíbrio de poder, isto é, há a alternância em quem controla ou exerce maior influência nas ações em distintos momentos ou situações. No que diz respeito à díade criada na interação professor-aluno, quando os estudantes se tornaram protagonistas nas ações ambientais desenvolvidas, gerou o sentimento de pertencimento e reciprocidade na participação efetiva no projeto, demonstrando a importância do estabelecimento do equilíbrio de poder.

O aparecimento das relações de afetividade tanto entre os estudantes, mas, mais propriamente entre professores e alunos tornou-se passível de destaque, influenciando, segundo a coordenadora pedagógica da instituição, inclusive na aprendizagem dos conteúdos, bem como, no comprometimento com outros projetos e dinâmicas que a escola oferta.

A proporção tomada pela ação do projeto que teve como protagonista a Educação Ambiental em um espaço de educação formal gerou a intencionalidade de que o mesmo se constitua em um "guarda-chuva" capaz de abarcar outras temáticas pertinentes ao cotidiano dos estudantes daquela instituição, sempre com um foco na tentativa da consolidação de uma sociedade mais justa e igualitária.

Quando se estabelecem processos de interação ambiental entre professor-aluno é perceptível que a díade se transforma em uma relação sistêmica indissociável: professor-aluno-ambiente. Essa relação ocorre através do princípio pertencimento e constitui um ambiente ecológico mais humanizado. Quando dimensionamos o social como parte constituinte do ambiente, compreendemos que o processo de humanização e desenvolvimento humano também é parte da rede sistêmica e complexa do mundo em que vivemos, conforme a analogia feita por Capra (1996): 
[...] quando vemos uma rede de relações entre folhas, ramos, galhos e tronco, chamamos isso de árvores. Ao desenhá-la, não faremos as raízes. No entanto, as raízes são tão notórias quanto às partes que vemos. Além disso, em uma floresta, as raízes estão interligadas e formam uma densa rede subterrânea na qual não há fronteiras precisas entre uma árvore e outra. (CAPRA, 1996, p. 49).

Neste momento, talvez, a escola F enquanto contexto ecológico que se constituiu, não perceba de maneira imediata as ações da proposta desenvolvida, mas, certamente, as raízes que foram interligadas nos processos proximais criados, são promotores do desenvolvimento humano para além dos sujeitos enquanto estudantes, mas sim, como seres ambientais.

\section{Referências}

BERDOULAY, Vincent e ENTRIKIN, J. Nicholas. Lugar e sujeito: perspectivas teóricas. In: MARANDOLA Jr., Eduardo; HOLZER, Werther; OLIVEIRA, Lívia de. Qual o espaço do lugar? Geografia, epistemologia, fenomenologia. São Paulo: Perspectiva, 2014.

BRASIL. Política Nacional de Educação Ambiental. Lei oㅜ 9795, de 27 de abril de 1999.

BRONFENBRENNER, Urie. A Ecologia do Desenvolvimento Humano: Experimentos Naturais e Planejados. Trad. Maria Adriana Veríssimo Veronesse. Porto Alegre: Artmed, 1996.

CAPRA, Fritjof. O Ponto de Mutação. São Paulo: Círculo do Livro, 1982.

CAPRA, Fritjof. A teia da vida: uma nova compreensão dos sistemas vivos. Tradução de Newton Roberval Eichemberg. São Paulo: Cultrix, 1996.

CECCONELLO, Alessandra Marques. KOLLER, Sílvia. Inserção Ecológica na comunidade: uma proposta metodológica para o estudo de famílias em situação de risco. In: KOLLER. Sílvia. (org.). Ecologia do desenvolvimento humano: pesquisa e intervenção no Brasil. São Paulo: Casa do Psicólogo, 2004.

CHAVEIRO, Eguimar Felício. Corporeidade e lugar: elos da produção da existência. In: MARANDOLA Jr., Eduardo; HOLZER, Werther; OLIVEIRA, Lívia de. Qual o espaço do lugar? Geografia, epistemologia, fenomenologia. São Paulo: Perspectiva, 2014.

CORTELLA, Mario Sergio. Qual é o papel da escola. Disponível em: https://www.youtube.com/watch?v=grobFdFDyF8. Acesso em: 11 de ago. de 2018. 
GRUN, Mauro. Ética e Educação Ambiental: A Conexão Necessária. Campinas: Papirus, 1996a.

JANKE, Nadja; TOZONI-REIS, Marília Freitas de Campos. Produção coletiva de conhecimentos sobre qualidade de vida: Por uma educação ambiental participativa e emancipatória. Ciência \& Educação, v. 14, n. 1, p. 147-157, 2008.

MEIRELLES, Maria de Sousa; SANTOS, Marly Terezinha. Educação Ambiental uma Construção Participativa. 2 $2^{\underline{a}}$ ed. São Paulo, 2005.

MELLO, João Baptista Ferreira de. 0 triunfo do lugar sobre o espaço. In: MARANDOLA Jr., Eduardo; HOLZER, Werther; OLIVEIRA, Lívia de. Qual o espaço do lugar? Geografia, epistemologia, fenomenologia. São Paulo: Perspectiva, 2014.

NARVAZ, Martha Giudice. KOLLER, Silvia Helena. Ecologia do Desenvolvimento Humano: pesquisa e intervenção no Brasil. São Paulo: Casa do Psicólogo, 2004.

POLETTO, Michele e KOLLER, Sílvia Helena. Contextos ecológicos: promotores de resiliência, fatores de risco e de proteção. Estudos de Psicologia (Campinas) v.25 n.3 Campinas jul./set. 2008. Disponível em: http://www.scielo.br/scielo.php?script=sci arttext\&pid=S0103166X2008000300009\&lng=pt\&nrm=iso. Acesso em: 11 de ago. de 2018.

OLIVEIRA, Lívia de. O sentido de lugar. In: MARANDOLA Jr., Eduardo; HOLZER, Werther; OLIVEIRA, Lívia de. Qual o espaço do lugar? Geografia, epistemologia, fenomenologia. São Paulo: Perspectiva, 2014.

TUDGE, Jonathan. A teoria de Urie Bronfenbrenner: uma teoria contextualista? In: MOREIRA, Lúcia; CARVALHO, Ana. Família e Educação: olhares da psicologia. São Paulo: Paulinas, 2008.

YUNES, Maria Ângela Mattar. JULIANO, Maria Cristina. A Bioecologia do Desenvolvimento Humano e suas Interfaces com Educação Ambiental. Cadernos de Educação (FaE/PPGE/UFPel), Pelotas, n. 37, p. 347 - 379, set./dez. https://periodicos.ufpel.edu.br/ojs2/index.php/caduc/article/viewFile/1591/1477. Acesso em: 10 ago. 2018. 